\title{
The mortality of Royal Naval submariners 1960-89
}

\author{
Hazel Inskip, Michael Snee, Leslie Styles
}

\begin{abstract}
Objectives-To examine the mortality pattern of submariners in the Royal Navy to assess the long term effects on health of serving in submarines. Any specific cause of death which was increased was considered in advance to be of interest, but attention focused particularly on cancer mortality.

Method-A mortality follow up study: 15138 submariners who had conducted their first submarine training between 1960 and 1979 were followed up through their time in the Navy and into civilian life, up to the end of 1989. The main outcome measures were the numbers of deaths and standardised mortality ratios (SMRs) which indicate whether the mortality from all causes and specific causes, particularly cancers, exceeds that in men in England and Wales.
\end{abstract}

Results-Mortality in submariners was lower than that for men in England and Wales with an all cause SMR of 86; this was comparable with that found in other studies of armed forces personnel. Cancer mortality was particularly low with an SMR of 69 and there was no particular cancer site which showed an excess. Increased mortality from digestive diseases was found, the excess being attributable to cirrhosis of the liver, which had an SMR of 221 based on 12 deaths, alcohol being a contributory factor in eight. Deaths from accidents and violence were also higher than expected with an SMR of 115 , but this was due to high levels of accidents occurring after discharge from the Navy. There was no apparent trend in mortality with time since starting submarine work. Likewise there was no pattern by calendar period, although the excess of cirrhosis of the liver was confined to the period 1970-9.

Conclusion-The submariners seemed to be a healthy group with low mortality overall. Working in submarines was not associated with any increased cancer mortality. Excess deaths from cirrhosis of the liver, and from accidents and violence after leaving the Navy, were of some concern but they cannot be attributed directly to the submarine environment.

\section{(Occup Environ Med 1997;54:209-215)}

Keywords: submariners; mortality; cancer; accidents; cirrhosis of liver
Submariners are exposed to a carefully monitored but artificial atmosphere, and some are also exposed to ionising radiation. Short term effects on health are monitored, although, in general, submariners are a healthy group. A study of rates of morbidity during 1969-74 showed that, for most diseases, the sickness admission and incidence of diseases for submariners were significantly lower than those for non-submariners within the Royal Navy. ${ }^{1}$ Such a study, however, gives no information about the long term effects on health which may only become apparent after the submariners have left the Navy. To assess this, Royal Navy personnel who first underwent training for submarine work between 1960 and 1979 have been followed up to the end of 1989 and their mortality pattern examined.

At the outset it was considered that excesses of deaths from any particular cause would be noteworthy, although the main focus was on cancer deaths as these might be related to atmospheric constituents in the submarine. The atmospheres of diesel and nuclear submarines differ, mainly because diesel submarines have to ventilate daily to recharge their batteries. Nuclear submarines, in contrast, can remain submerged for long periods and the atmosphere is recycled. ${ }^{2-4}$ Radiation exposures have been minimal at sea, even in the early days of nuclear submarines. Exposures do occur, however, during maintenance and repair work within the reactor compartment. ${ }^{2}$ For many nuclear submariners, radiation exposure is lower than that from natural background radiation as they are protected against the effect of cosmic rays while submerged.

During the study period, both diesel and nuclear submarines were in use in the Royal Navy. This study does not distinguish between the two types of submarine service, some submariners having served in both types. Extracting the details of individual patrols for each submariner would have been an extremely complex task. It was considered that this could be explored later in nested casecontrol studies should excesses of any particular cause of death arise in the whole study population.

\section{Methods}

STUDY POPULATION

No lists of submariners for the period of interest exist in the Royal Navy and so study participants were identified from the submarine escape training tank (SETT) records held at HMS Dolphin. All Naval personnel who serve 
in submarines must undergo training at the escape tank and this has to be repeated periodically by active submariners. The SETT records for personnel in the Royal Navy contained the name and date of training, and for most men, the service number was also recorded. Before 1972, officers were not issued with service numbers. Records also existed for members of foreign navies and civilians who underwent training at HMS Dolphin. Many people had more than one record, particularly if they had two or more separate periods of submarine service.

To identify which of these records referred to submariners in the Royal Navy and to obtain the information required for long term follow up of study members, the Royal Navy personnel records at HMS Centurion were consulted. In this way full names, date, and place of birth, National Health Service number, National Insurance number, and date of leaving the Navy were obtained when available. Also a computer tape was accessed which contained details of all submariners since 1972. From this it was possible to identify which of the submariners were still in service on 31 December 1989. All such men were assumed to be alive on that date.

All data extraction from records at HMS Dolphin and HMS Centurion was performed by two clerks. They entered the information into the computer, their two sets of data were compared, and any discrepancies were resolved.

The study received ethical approval from the BMA Ethics Committee. All data relating to individual men were kept in locked filing cabinets within the Medical Research Council (MRC) Environmental Epidemiology Unit which is registered under the Data Protection Act for conducting research of this nature.

FOLLOW UP

For all submariners who had been discharged before the end of 1989 , cards containing relevant identifying information were prepared. These were sent to the National Health Service Central Register (NHSCR) to obtain information on whether the people were alive, dead, emigrated, or untraced. Death certificates were obtained for those who had died, and causes of death were coded according to the ninth revision of the international classification of diseases (ICD-9) 5 by the Office of Population Censuses and Surveys (OPCS).

The armed forces have their own medical service which is not part of the National Health Service. Thus forces personnel are not actively registered at the NHSCR during their period of service. Therefore, information about mortality or emigration occurring within the forces is not complete in that register. Once people have left the forces they may register with an NHS doctor and then have an active record in the NHSCR. However, some never register or do so many years later, either because they have emigrated immediately upon leaving the services or because they do not require a doctor. Although the NHSCR contains records of deaths occurring in the
Navy for some people, it is known that some are missed, particularly if the deaths occurred abroad. To identify deaths occurring in service, the records of all deaths occurring in the Royal Navy were extracted from the registers and put on to computer. This file was then linked to the file of submariners by name and service number to identify the in-service deaths in the cohort. The details of the deaths about which no information had been received from the NHSCR were extracted and efforts were made by the NHSCR to locate a death certificate. When this was impossible, the causes of death as described in the Naval medical records were coded by the OPCS.

The Royal Navy's death registers were only available from 1966. To ensure that earlier deaths were not missed, the Naval medical records were examined for each submariner in the study who had left the Navy before 1966 and for whom there was no tracing information available after they left the Navy.

In limited circumstances, such as for medical research purposes, the Department of Social Security (DSS) can also provide help with tracing when National Insurance numbers are available. It was thus possible to trace a further 496 people who were otherwise untraced, or for whom no trace could be found at the NHSCR beyond their periods of service in the Navy. The DSS provided information about whether each person was alive or dead, and dates of death when appropriate. Once the dates were available, some of the causes of death could be found in the NHSCR.

\section{STATISTICAL METHODS}

Efforts were made to identify a suitable control group from within the Navy. This, however, proved impossible as submariners are selected on health grounds and there was no other readily identifiable group of sufficient size for which similar restrictions were made. A comparison with the general population was therefore made using national mortality rates. These have the advantage of being based on many people and are therefore stable. As noted above, it was considered that if any particular cause of death gave rise to concern, then a nested case-control study could be carried out within the cohort of submariners. In this way, submariners who had died could be compared with other submariners who had been selected similarly for submarine work.

For the comparison with national rates, standard methods of analysis for cohort studies were used. ${ }^{6}$ Person-years at risk were calculated for the entire study population, with the date of entry to the study for each submariner being the date of his first SETT record. As those in service on 31 December 1989 were not followed up, person-years for the study population were not calculated beyond that date. Expected numbers of deaths from all causes and various specific causes were calculated by multiplying the person-years at risk in five-year age groups and calendar periods by the appropriate rates for men in England and Wales. The national rates were bridge-coded 
Table 1 Number of eligible men, number excluded, and number in the study

\begin{tabular}{lr}
\hline $\begin{array}{l}\text { Number of eligible men } \\
\text { Excluded men } \\
\text { Number with insufficient } \\
\text { information for tracing }\end{array}$ & 15314 \\
Number untraced and with & 176 \\
$\quad$ no date of leaving the Navy & 145 \\
Latest date traced before & \\
$\quad$ lst SETT training date & 5 \\
Number in analysis & 26 \\
\hline
\end{tabular}

to the ICD-9 to take account of changes in the coding system over time. Ratios of the observed to expected deaths were calculated to give standardised mortality ratios (SMRs) which were expressed as a percentage. Thus an SMR of 100 would mean that the mortality of this group of submariners was the same as that of men in England and Wales. The 95\% confidence intervals ( $95 \% \mathrm{CIs)} \mathrm{were} \mathrm{calcu-}$ lated with tables of the Poisson distribution.

In analysing the mortality from specific neoplasms, the latent periods between initiation of the tumours and death were taken into account. Latent periods vary with cancer site and can be as long as 25 to 30 years. It is impossible to examine such long latent periods in a study which only spans 30 years but, to take some account of latency, three analyses were conducted in which two, five, and 10 years respectively were allowed to elapse before starting to count the person-years at risk and the numbers of deaths.

A potential bias existed in that a man about whom there was little information available would be more likely to be traced if he had died than if he were still alive. This could arise, for example, if a submariner never registered with a general practitioner after leaving the Navy but his death was notified to the NHSCR under the standard procedure. To examine the effect of this bias on the analysis, all those who were not traced beyond their

Table 2 Numbers of observed deaths and SMRs (95\% CIs) for selected causes of death

\begin{tabular}{|c|c|c|c|}
\hline Cause $(I C D-9)$ codes & Obs & $S M R$ & $(95 \% C I)$ \\
\hline \multicolumn{3}{|l|}{ Cancer of: } & (52 to 89 ) \\
\hline Oesophagus (150) & 3 & 127 & $(26$ to 370$)$ \\
\hline Stomach (151) & 5 & 113 & ( 37 to 264 ) \\
\hline Colon (153) & 5 & 101 & ( 33 to 236 ) \\
\hline Pancreas (157) & 4 & 136 & (37 to 349 ) \\
\hline Lung (162-164) & 10 & 62 & (30 to 114 ) \\
\hline Brain (191-192) & 3 & 39 & (8 to 115$)$ \\
\hline \multirow{3}{*}{$\begin{array}{l}\text { Melanoma }(172) \\
\text { Non-Hodgkin's lymphoma }(200,202 \cdot 0, \\
202 \cdot 1,202 \cdot 8) \\
\text { Leukaemia }(204-208)\end{array}$} & 4 & 139 & (38 to 356$)$ \\
\hline & 3 & 65 & (13 to 190$)$ \\
\hline & 5 & 74 & (24 to 173$)$ \\
\hline Endocrine, nutritional, and metabolic & 3 & 44 & (9 to 130$)$ \\
\hline Circulatory diseases $(390-459)$ & 71 & 65 & (51 to 82$)$ \\
\hline Respiratory diseases $(460-519)$ & 5 & 28 & (9 to 65$)$ \\
\hline $\begin{array}{l}\text { Digestive diseases }(008-009,520-579) \\
\text { Cirrhosis of liver (571) }\end{array}$ & $\begin{array}{l}18 \\
12\end{array}$ & $\begin{array}{l}165 \\
221\end{array}$ & $\begin{array}{l}(98 \text { to } 261) \\
(114 \text { to } 387)\end{array}$ \\
\hline \multirow{10}{*}{$\begin{array}{l}\text { Accidents and violence (E800-E999) } \\
\text { Motor vehicle traffic accidents (E810-E819) } \\
\text { Water transport accidents (E830-E838) } \\
\text { Accidental poisoning (E850-E869) } \\
\text { Accidental poisoning by alcohol (E860) } \\
\text { Accidental falls (E880-E888) } \\
\text { Accidental drowning (E910) } \\
\text { Suicide (E950-E959) } \\
\text { Homicide (E960-E969) } \\
\text { Injury undetermined whether accidentally } \\
\text { or purposely inflicted (E980-E989) }\end{array}$} & 153 & 115 & (98 to 135 ) \\
\hline & 58 & 118 & (90 to 153$)$ \\
\hline & 2 & 129 & (16 to 464 ) \\
\hline & 6 & 101 & (37 to 221 ) \\
\hline & 4 & 417 & (114 to 1068$)$ \\
\hline & 7 & 109 & (44 to 224 ) \\
\hline & 10 & 326 & (156 to 599$)$ \\
\hline & 34 & 98 & (68 to 137$)$ \\
\hline & 1 & 32 & $(1$ to 180$)$ \\
\hline & 11 & 96 & (48 to 171$)$ \\
\hline All causes $(000-999)$ & 340 & 86 & (77 to 95$)$ \\
\hline
\end{tabular}

departure from the Royal Navy were assumed to be alive on 31 December 1989 and the analysis was re-run.

Efforts were also made to estimate the number of deaths which might have been missed in the tracing process. The proportion of deaths was calculated among those not traced at the NHSCR but traced in the DSS because they had National Insurance numbers. This was used to estimate the number of deaths expected in those untraced at the NHSCR for whom National Insurance numbers were not available. Estimates of missed in-service deaths were also made by comparing the numbers of in-service deaths identified in the NHSCR and in the Navy death registers and medical records.

\section{Results}

STUDY POPULATION

There were 15314 people eligible for study in that they had been identified from the SETT records at HMS Dolphin and their details were found in the Royal Navy personnel records. Table 1 shows why 176 of these could not be included in the analysis. Thus there were 15138 submariners included in the analysis, providing a total of 278166 personyears of follow up. Within the group available for analysis, there were 303 men who had not died in service but for whom no information was available after discharge. These could only be included in the analysis during their period in the Navy. On 31 December 1989, 3575 of the submariners were still serving in the Navy and so were known to be alive on that date.

Between 1960 and 1989, 340 submariners died, of whom 109 died in service. No cause of death was available for 28 of the deaths, usually because the death occurred abroad or the body was never found.

\section{MORTALITY}

Table 2 shows the SMRs for broad groups of causes and several specific causes of death. The SMR for all causes was 86 whereas the SMRs for circulatory diseases and all malignant neoplasms were still lower at 65 and 69 respectively. Among broad cause groups, the SMR for respiratory diseases was particularly low at 28. Table 2 also gives the SMRs for all specific types of neoplasm with more than two deaths, and accidental causes of interest.

There were more deaths from digestive diseases than expected giving an SMR of 165 (95\% CI 98 to 261 ). The excess was entirely explained by the 12 deaths from cirrhosis of the liver, seven of which had alcohol specifically mentioned on the death certificate. Three men who died from cirrhosis were noted in the Naval medical records as having been heavy drinkers or alcoholics, but for one of these, alcohol was not mentioned on the death certificate. Two others were noted as having had accidents after a drinking session, and both of these had alcohol mentioned on their death certificates. Others may have been drinkers, but the fact went unreported in the records because it did not come to medical attention 
Table 3 Numbers of observed deaths and SMRs (95\% CIs) for broad cause groups by calendar period

\begin{tabular}{|c|c|c|c|c|c|c|c|c|c|}
\hline \multirow[b]{3}{*}{ Cause } & \multicolumn{9}{|c|}{ Calendar period } \\
\hline & \multicolumn{3}{|c|}{$1960-9$} & \multicolumn{3}{|c|}{$1970-9$} & \multicolumn{3}{|c|}{$1980-9$} \\
\hline & Obs & $S M R$ & $(95 \%$ CI) & Obs & $S M R$ & $(95 \%$ CI) & Obs & $S M R$ & $(95 \% C I)$ \\
\hline $\begin{array}{l}\text { All malignant neoplasms } \\
\text { Circulatory disease } \\
\text { Respiratory disease } \\
\text { Digestive disease } \\
\text { Accidents and violence }\end{array}$ & $\begin{array}{r}3 \\
0 \\
0 \\
0 \\
21\end{array}$ & $\begin{array}{r}67 \\
0 \\
0 \\
0 \\
119\end{array}$ & $\begin{array}{l}(14 \text { to } 196) \\
(0 \text { to } 100) \\
(0 \text { to } 186) \\
(0 \text { to } 601) \\
(74 \text { to } 182)\end{array}$ & $\begin{array}{r}14 \\
17 \\
1 \\
8 \\
53\end{array}$ & $\begin{array}{r}68 \\
72 \\
16 \\
615 \\
105\end{array}$ & $\begin{array}{l}(37 \text { to } 114) \\
(42 \text { to } 115) \\
(0 \text { to } 90) \\
(266 \text { to } 1212) \\
(79 \text { to } 137)\end{array}$ & $\begin{array}{r}39 \\
54 \\
5 \\
10 \\
79\end{array}$ & $\begin{array}{r}69 \\
67 \\
40 \\
111 \\
122\end{array}$ & $\begin{array}{l}(49 \text { to } 95) \\
(50 \text { to } 87) \\
(11 \text { to } 103) \\
(53 \text { to } 204) \\
(96 \text { to } 152)\end{array}$ \\
\hline All causes & 26 & 79 & (52 to 116 ) & 106 & 90 & (74 to 109 ) & 208 & 85 & (74 to 97 ) \\
\hline
\end{tabular}

Table 4 Numbers of observed deaths and SMRs (95\% CIs) for broad cause groups by time since first submarine training

\begin{tabular}{|c|c|c|c|c|c|c|c|c|c|}
\hline \multirow[b]{3}{*}{ Cause } & \multicolumn{9}{|c|}{ Time since first submarine training } \\
\hline & \multicolumn{3}{|c|}{$<10 y$} & \multicolumn{3}{|c|}{$10-19 y$} & \multicolumn{3}{|c|}{$20-29 y$} \\
\hline & Obs & $S M R$ & $(95 \% C I)$ & Obs & $S M R$ & $(95 \% C I)$ & Obs & $S M R$ & $(95 \% C I)$ \\
\hline $\begin{array}{l}\text { All malignant neoplasms } \\
\text { Circulatory disease } \\
\text { Respiratory disease } \\
\text { Digestive disease } \\
\text { Accidents and violence }\end{array}$ & $\begin{array}{r}11 \\
12 \\
3 \\
3 \\
92\end{array}$ & $\begin{array}{r}52 \\
67 \\
42 \\
140 \\
120\end{array}$ & $\begin{array}{l}(26 \text { to } 94) \\
(35 \text { to } 118) \\
(9 \text { to } 121) \\
(29 \text { to } 409) \\
(97 \text { to } 147)\end{array}$ & $\begin{array}{r}22 \\
29 \\
1 \\
9 \\
45\end{array}$ & $\begin{array}{r}66 \\
61 \\
15 \\
183 \\
103\end{array}$ & $\begin{array}{l}(41 \text { to } 100) \\
(41 \text { to } 87) \\
(0 \text { to } 82) \\
(84 \text { to } 347) \\
(75 \text { to } 137)\end{array}$ & $\begin{array}{r}23 \\
30 \\
1 \\
6 \\
16\end{array}$ & $\begin{array}{r}85 \\
70 \\
25 \\
156 \\
129\end{array}$ & $\begin{array}{l}(54 \text { to } 128) \\
(47 \text { to } 100) \\
(1 \text { to } 137) \\
(57 \text { to } 340) \\
(74 \text { to } 210)\end{array}$ \\
\hline All causes & 136 & 94 & (79 to 111$)$ & 119 & 77 & (64 to 92 ) & 85 & 87 & (70 to 108 ) \\
\hline
\end{tabular}

when they were in service. Comparison of the 12 deaths from cirrhosis with the $5 \cdot 4$ expected on the basis of English and Welsh rates gave an SMR of 221 (95\% CI 114 to 387) for this cause.

Deaths from accidents and violence were slightly higher than expected with an SMR of

Table 5 Numbers of observed deaths and SMRs (95\% CIs) for specific malignancies allowing for a 10 year latent period

\begin{tabular}{lccl}
\hline Type of cancer & Obs & SMR & (95\% CI) \\
\hline Oesophagus & 3 & 138 & $(29$ to 404$)$ \\
Stomach & 4 & 106 & $(29$ to 272) \\
Colon & 4 & 96 & $(26$ to 247) \\
Pancreas & 4 & 153 & $(42$ to 391$)$ \\
Lung & 7 & 49 & $(20$ to 101$)$ \\
Brain & 2 & 39 & $(5$ to 140$)$ \\
Melanoma & 4 & 193 & $(53$ to 493$)$ \\
Non-Hodgkin's lymphoma & 2 & 66 & $(8$ to 239$)$ \\
Leukaemia & 4 & 11 & $(30$ to 283$)$ \\
All malignant neoplasms & 45 & 75 & $(55$ to 100$)$ \\
\hline
\end{tabular}

Table 6 In-service mortality: numbers of observed deaths and SMRs (95\% CIs) for selected causes of death

\begin{tabular}{|c|c|c|c|}
\hline Cause & Obs & SMR & $(95 \% C I)$ \\
\hline $\begin{array}{l}\text { All malignant neoplasms } \\
\text { Cancer of: }\end{array}$ & 9 & 35 & (16 to 66$)$ \\
\hline $\begin{array}{l}\text { Oesophagus } \\
\text { Stomach } \\
\text { Colon } \\
\text { Pancreas } \\
\text { Lung } \\
\text { Brain } \\
\text { Melanoma } \\
\text { Non-Hodgkin's lymphoma } \\
\text { Leukaemia }\end{array}$ & $\begin{array}{l}1 \\
2 \\
0 \\
1 \\
0 \\
1 \\
0 \\
2 \\
0\end{array}$ & $\begin{array}{r}213 \\
187 \\
0 \\
155 \\
0 \\
35 \\
0 \\
112 \\
0\end{array}$ & $\begin{array}{l}(5 \text { to } 1186) \\
(23 \text { to } 675) \\
(0 \text { to } 285) \\
(4 \text { to } 865) \\
(0 \text { to } 111) \\
(1 \text { to } 193) \\
(0 \text { to } 355) \\
(14 \text { to } 405) \\
(0 \text { to } 116)\end{array}$ \\
\hline $\begin{array}{l}\text { Endocrine, nutritional, and } \\
\text { metabolic diseases }\end{array}$ & 1 & 40 & (1 to 223 ) \\
\hline Circulatory diseases & 13 & 46 & (25 to 79 ) \\
\hline Respiratory diseases & 3 & 40 & ( 8 to 118 ) \\
\hline $\begin{array}{l}\text { Digestive diseases } \\
\text { Cirrhosis of liver }\end{array}$ & $\begin{array}{l}2 \\
0\end{array}$ & $\begin{array}{r}61 \\
0\end{array}$ & $\begin{array}{l}(7 \text { to } 221) \\
(0 \text { to } 257)\end{array}$ \\
\hline $\begin{array}{l}\text { Accidents and violence } \\
\text { Motor vehicle traffic accidents } \\
\text { Water transport accidents } \\
\text { Accidental poisoning } \\
\text { Accidental poisoning by alcohol } \\
\text { Accidental falls } \\
\text { Accidental drowning } \\
\text { Suicide } \\
\text { Homicide } \\
\text { Injury undetermined whether }\end{array}$ & $\begin{array}{r}73 \\
37 \\
0 \\
4 \\
2 \\
2 \\
7 \\
12 \\
0\end{array}$ & $\begin{array}{r}101 \\
119 \\
0 \\
133 \\
556 \\
64 \\
378 \\
74 \\
0\end{array}$ & $\begin{array}{l}(79 \text { to } 127) \\
(84 \text { to } 164) \\
(0 \text { to } 394) \\
(36 \text { to } 340) \\
(67 \text { to } 2008) \\
(8 \text { to } 232) \\
(152 \text { to } 778) \\
(38 \text { to } 129) \\
(0 \text { to } 222)\end{array}$ \\
\hline \multicolumn{2}{|l|}{$\begin{array}{l}\text { Injury undetermined whether } \\
\text { accidentally or purposely inflicted } 0\end{array}$} & 0 & (0 to 72$)$ \\
\hline All causes & 109 & 69 & (57 to 84 ) \\
\hline
\end{tabular}

115 (95\% CI 98 to 135). The largest single cause of accidental death was due to motor vehicle traffic accidents with an SMR of 118 (95\% CI 90 to 153). The next largest cause was suicide with an SMR of 98. A threefold excess of deaths from accidental drowning was apparent, and deaths from accidental poisoning by alcohol were four times higher than expected, although there were only four deaths from this cause.

Table 3 gives the SMRs for broad cause groups by calendar period. Deaths from digestive diseases were particularly high in the middle period, 1970-9, with an SMR of 615 but there were no strong trends in the SMRs across the three periods for any of these cause groups. The excess of cirrhosis of the liver was concentrated in the period 1970-9 for which the SMR was 729 (95\% CI 268-1587) based on six deaths. The remaining six deaths from this cause all occurred in the period 1980-9, but this number was much closer to that expected from national rates, with the SMR being 133 (95\% CI 49-289).

Table 4 presents the SMRs for broad cause groups by time since entering the study. There was no apparent trend in the SMRs over the three periods except weakly for malignant neoplasms. When examining specific malignancies allowing for two, five, and 10 year latent periods, there was no clear excess from any particular cancer site. Table 5 shows the SMRs allowing for a 10 year latency.

Tables 6 and 7 show the results of the analysis of mortality in service and after leaving the Navy. For 104 submariners, no date of leaving the Navy was found in the records although it was known that they had left before the end of 1989 , so they had to be excluded from these analyses. Eleven of these submariners had died and one of them had died in service, but as his date of leaving the Navy was only found in the death register and not the personnel records this man had to be excluded from the analysis of in-service mortality. Mortality was particularly low during 
Table 7 Mortality after leaving the Navy: numbers of observed deaths and SMRS (95\% CIs) for selected causes of death

\begin{tabular}{|c|c|c|c|}
\hline Cause & Obs & $S M R$ & $(95 \% C I)$ \\
\hline $\begin{array}{l}\text { All malignant neoplasms } \\
\text { Cancer of: }\end{array}$ & 45 & 86 & $(62$ to 114$)$ \\
\hline $\begin{array}{l}\text { Oesophagus } \\
\text { Stomach } \\
\text { Colon } \\
\text { Pancreas } \\
\text { Lung } \\
\text { Brain } \\
\text { Melanoma } \\
\text { Non-Hodgkin's lymphoma } \\
\text { Leukaemia }\end{array}$ & $\begin{array}{r}2 \\
3 \\
4 \\
2 \\
10 \\
2 \\
4 \\
1 \\
5\end{array}$ & $\begin{array}{r}111 \\
95 \\
115 \\
92 \\
84 \\
43 \\
222 \\
36 \\
144\end{array}$ & $\begin{array}{l}(14 \text { to } 402) \\
(20 \text { to } 279) \\
(31 \text { to } 294) \\
(11 \text { to } 333) \\
(40 \text { to } 154) \\
(5 \text { to } 156) \\
(61 \text { to } 569) \\
(1 \text { to } 202) \\
(47 \text { to } 335)\end{array}$ \\
\hline $\begin{array}{l}\text { Endocrine, nutritional, and } \\
\text { metabolic diseases }\end{array}$ & 2 & 48 & (6 to 175 ) \\
\hline Circulatory diseases & 55 & 72 & (54 to 94 ) \\
\hline Respiratory diseases & 2 & 20 & ( 2 to 72 ) \\
\hline $\begin{array}{l}\text { Digestive diseases } \\
\text { Cirrhosis of liver }\end{array}$ & $\begin{array}{l}14 \\
10\end{array}$ & $\begin{array}{l}189 \\
258\end{array}$ & $\begin{array}{l}(103 \text { to } 317) \\
(124 \text { to } 474)\end{array}$ \\
\hline $\begin{array}{l}\text { Accidents and violence } \\
\text { Motor vehicle traffic accidents } \\
\text { Water transport accidents } \\
\text { Accidental poisoning } \\
\text { Accidental poisoning by alcohol } \\
\text { Accidental falls } \\
\text { Accidental drowning } \\
\text { Suicide } \\
\text { Homicide }\end{array}$ & $\begin{array}{r}78 \\
21 \\
2 \\
2 \\
2 \\
5 \\
3 \\
22 \\
1\end{array}$ & $\begin{array}{r}131 \\
119 \\
331 \\
70 \\
339 \\
154 \\
252 \\
121 \\
70\end{array}$ & $\begin{array}{l}(104 \text { to } 163) \\
(74 \text { to } 182) \\
(40 \text { to } 1194) \\
(9 \text { to } 253) \\
(41 \text { to } 1223) \\
(50 \text { to } 359) \\
(52 \text { to } 736) \\
(76 \text { to } 182) \\
(2 \text { to } 393)\end{array}$ \\
\hline \multicolumn{2}{|l|}{$\begin{array}{l}\text { Injury undetermined whether } \\
\text { accidentally or purposely inflicted } 10\end{array}$} & 158 & (76 to 291 ) \\
\hline All causes & 220 & 96 & $(84$ to 110$)$ \\
\hline
\end{tabular}

service in the Navy with the SMR for all causes being 69 . After leaving the Navy, all cause mortality was close to the national average for men with an SMR of 96, but accidental and violent deaths were particularly high with an SMR of 131 (95\% CI 104-163). The excess mortality from cirrhosis of the liver occurred in men who had left the Navy.

When all those who were untraced were assumed to be alive on 31 December 1989, the SMRs for the study changed little. The all cause SMR decreased from 86 to 84 and that for all malignant neoplasms fell from 69 to 67 .

Missed deaths are of concern, as they would bias the SMRs downwards. Some of the 303 men who were not traced beyond their period of service may have died, possibly abroad, resulting in a deficit of deaths. Additionally, some in-service deaths may have been missed. Tables 8 and 9 show estimations of the numbers of missed deaths in these groups, from which it seems that the number missed is about 10 .

Table 8 Estimation of the number of missed deaths among those not traced in the NHSCR

\begin{tabular}{|c|c|c|}
\hline & \multicolumn{2}{|c|}{ Not traced in the NHSCR } \\
\hline & $\begin{array}{l}\text { With National } \\
\text { Insurance number }\end{array}$ & $\begin{array}{l}\text { Without National } \\
\text { Insurance number }\end{array}$ \\
\hline $\begin{array}{l}\text { Deaths found at DSS } \\
\text { Total }\end{array}$ & $\begin{array}{r}13 \\
496\end{array}$ & $\begin{array}{l}x^{\star} \\
303\end{array}$ \\
\hline
\end{tabular}

Table 9 Estimation of missed in-service deaths

\begin{tabular}{lll}
\hline & NHSCR \\
\cline { 2 - 3 } & Not found & Found \\
\hline $\begin{array}{ll}\text { Navy death register: } \\
\begin{array}{l}\text { Not found } \\
\text { Found }\end{array}\end{array}$ & $\mathrm{y}^{\star}$ & 5 \\
\hline
\end{tabular}

$\star$ Estimated value of $y=\frac{5 \times 28}{76}=2$ missed deaths.
Discussion

ALL CAUSE MORTALITY

The SMR of 86 recorded for submariners is broadly in line with those reported for many occupational groups, ${ }^{8}$ and in particular, for other armed forces personnel, ${ }^{9-12}$ for whom the SMRs ranged from 79 to 87 in different periods. Such low SMRs are commonly found in occupational groups as they show what is known as the healthy worker effect. ${ }^{13} \mathrm{~A}$ strong healthy worker effect would be expected in submariners as they are selected on health grounds. Not surprisingly therefore, mortality in those serving in the Navy was particularly low with an SMR of 69, but after discharge, mortalities were close to those for England and Wales. The SMRs reported here are, however, somewhat higher than the SMR of 62 found for submariners in the United States when compared with the United States male population. ${ }^{14}$

MORTALITY FROM SPECIFIC CAUSES

When considering analyses of specific causes of death, the inaccuracies that can occur on death certificates must be borne in mind. ${ }^{15}$ Information on deaths was obtained from two sources, namely the NHSCR and the Navy death records, and this may have caused a bias when comparing with deaths recorded in England and Wales. For only four deaths was the cause of death obtained solely from Navy death records rather than from an official death certificate. Some deaths occurred abroad, but it is not clear how many would have featured in the national rates against which comparisons have been made in this study. It is possible that biases in the cause specific mortality ratios have arisen as a result of information being drawn from more than one source.

The particularly low mortality from respiratory disease is likely to be a real effect which can be explained by selection on health grounds; those with respiratory problems are not allowed into the submarine service. Cancer mortality is thought to be less affected by selection, so the all cancer SMR of 69 found here is remarkably low. With this SMR being lower than that for all causes and comparable with that for circulatory disease it seems that, during the period under study, the submarine environment did not increase the risk of cancer. It is noteworthy that the results for mortality from all cancers and cardiovascular disease were similar to the findings of a study of United States submariners in which the SMRs were about 70 for both causes. ${ }^{14}$ However, as our study only had an average follow up of 18 years, the possibility of excess cancers with long latent periods cannot be ruled out.

Although the power was low for examining particular cancer sites, there was no evidence of excesses of any specific cancers within the follow up period. Notably, deficits of lung cancers and leukaemia were observed and these are malignancies which might have been associated with exposures that occur in the internal submarine environment, such as radiation. 
Nuclear submariners generally have low radiation exposures, and indeed, due to the protection from cosmic rays, some may have lower exposures than the general population. This is unlikely to explain the cancer deficits, but the lack of excesses is certainly encouraging. Sadly, of course, no specific information was available on exposure of individual men, either in terms of duration at sea, or to specific carcinogens. However, if some aspect of the submarine service had given rise to an increase in cancer, the effect must either have been very small, or the submariners with low exposures must have had remarkably low cancer mortality.

The high mortality from cirrhosis of the liver is of some concern but it is most unlikely to be related to the submarine environment. Among the 12 men who died from this cause, eight had alcohol mentioned on their death certificates or were noted in the Naval medical records as having been heavy drinkers or alcoholics. Thus it seems that alcohol was a factor in most deaths from this cause. Excess mortality from diseases related to alcohol, including cirrhosis of the liver, was reported for Naval personnel within a study of mortality among United Kingdom servicemen who served abroad in the 1950s and 1960s. ${ }^{11}$ An SMR of 229 was found when rates for England and Wales were used as the standard, but the excess was almost sevenfold in comparison with rates for Army and Royal Air Force personnel. In that study, it was suggested that the excess might be due to the duty-free alcohol which is available to all members of the three services while abroad, and to provision of alcohol to Naval personnel. In the current study of submariners, the excess was greatest in the decade 1970-9 and was hardly evident in the 1980 s, although there were six deaths from this cause in each period. Comparing the 1980 s with the 1970 s, there were more person-years at risk in the study population which was also older and thus at greater risk of cirrhosis. Between the early 1970s and the late 1980 s the rates in the national population approximately doubled, but this is not sufficient to explain the difference in excess mortality in submariners between the two decades. It is noteworthy, however, that death rates for this cause not only vary over time, but also geographically; rates in Scotland, for example, are about double those in England and Wales and they too have doubled throughout the period of this study. This is of relevance as some submariners are from Scotland and some are based there. The encouraging point from this study is, however, that extrapolation of the decline in mortality from this cause in submariners between the 1970 s and 1980 s suggests that the disease is now of less concern in this group.

There were 28 deaths for which no cause could be assigned. Although they were included in the assessment of all cause mortality they could not feature in any of the cause specific analyses. Three men who participated in the Falklands conflict were noted as "missing, presumed dead", but, although in the
Navy, they were not serving as submariners at the time. There were six men for whom drowning was the likely cause as they fell overboard, but, because their bodies were never found, the cause could not be ascertained. For one additional death, the place of death was a highway and so it was probably a road traffic accident. For the remaining 18 deaths, no information was available about the cause of death, and for six of these the only source of the fact of death was the Department of Social Security records. The usual reason for no cause being given was because the death occurred abroad and only the date of death could be found.

With 10 of the deaths from unknown causes seeming to be accidental, the SMR of 115 for accidents and violence is likely to be an underestimate. Even when considering these extra accidental deaths in the analysis, the excess was confined to the period after the submariners left the Navy. This indicates that submarine service itself does not increase the risk of accidental or violent death. The only exception is accidental drowning from which there were seven documented deaths in service; given that the population are at sea, this comes as no surprise.

There is no obvious explanation of the excess after discharge from the Navy, although risk taking may have increased when people were freed from the discipline of the services, and, as for cirrhosis of the liver, alcohol may have played a part. Deaths (but only four) from accidental poisoning by alcohol did, however, occur both in service and after discharge. Accidents comprised the largest specific cause group by far which is not surprising in a young cohort, but it is of concern that when the submariners returned to civilian life their mortality from this cause was significantly higher than for the rest of the civilian population. The excess mortality from accidents and violence in ex-submariners could not be attributed to one type of accident alone. Most of these deaths were due to traffic accidents and suicide, both SMRs being increased, but only slightly over 100 . There were only a few deaths from other specific types of accidents, but table 7 shows a pattern of increased mortality from a broad range of accidental causes. Rafnsson and Gunnarsdóttir also found excesses of a variety of accidental causes in an analysis of deaths in seamen. ${ }^{16}$ They identified an association between duration of employment and fatal accidents, and suggested that the occupation may have modified behaviour towards more risk taking. Duration of employment could not be analysed here, as we do not know how long the submariners were in the Navy before joining the submarine service. It is possible that patterns of risk taking contributed towards the results reported here, although the absence of excess mortality in service would argue against such behaviour developing while in the Navy.

\section{POSSIBLE BIASES}

Considerable difficulty was experienced in linking the original SETT records with the 
personnel information at HMS Centurion. Several possible matches that were found were rejected because the information did not make sense. Thus a few seemed to have done their SETT training after they had left the Navy or before they were old enough to enlist. The number of such inappropriate links is not known, as in general the clerks made the decision as to whether a link had been established or not; some were, however, rejected after later checking. A number of other incorrect links may also have been made, but were not excluded because there was no obvious problem with the data. Additionally, 145 submariners had to be excluded because it was impossible to find sufficient information in the records to enable tracing of these men. There is no obvious reason to suspect that these men had a higher death rate than those in the study but the possibility of bias cannot be ruled out.

Each submariner was identified from the SETT records which only indicate that he underwent training, not that he was an active submariner. Thus the study population may include some people who, although correctly identified in the records, were never exposed to the submarine environment.

Any bias towards overestimating the deaths is likely to be small given that the all cause SMR only reduced from 86 to 84 when all those who were untraced beyond their period of service in the Navy were assumed to be alive.

Of greater concern is the bias due to missed deaths in this group, although it seems that the number is only of the order of 10 . It is unlikely, therefore, that results are seriously biased by the deaths that were not identified.

\section{Conclusion}

The submariners in this study seemed to be a healthy group of men who experienced low mortality when compared with men in England and Wales. There was no evidence that submarine work led to an increase in mortality from cancer of any site, and there was a deficit of cancer deaths in submariners when compared with the national population. The high mortality from cirrhosis of the liver in the 1970s had declined considerably by the 1980 s relative to rates in the civilian population of England and Wales. Deaths from accidents and violence were also somewhat higher than expected but the excess occurred among those who had left the Navy.

This study was initiated by Professor Martin Gardner who sadly did not live to see its completion. Considerable help was received throughout the study from many members of the Royal Navy, particularly the staff at HMS Dolphin and HMS Centurion and the officers who, during the period of the study, held the posts of Senior Medical Officer (Submarine Medicine) and Submarine Flotilla Medical Officer. We acknowledge the work done by Jenny Start and Sheila Nicklen in extracting the data and the staff of the NHSCR and DSS in tracing the study participants. Much help was received from the Medical Research Council's Royal Naval Personnel Research Committee and its subgroup on epidemiological studies in submariners chaired by Professor Ron Linden and with Roberta Withnall as secretary. The study was funded by the Ministry of Defence and the Medical Research Council.

1 Davies DM, Sowden RR, Jolly EJ. Morbidity in the $R N$ Submarine Service 1969-74. Alverstoke, Hampshire: Institute of Naval Medicine 1975. (Report No 10/75.)

2 Lambert RJW. Problems of radiation and hygiene in enclosed spaces-submarines. Ann Occup Hyg 1968;11: enclosed

3 Lambert RJW. Environmental problems in nuclear submarines. Proc $R$ Soc Med 1972;65:795-6.

4 Davies DM. Sixty days in a submarine: the pathophysiological and metabolic cost. $\mathcal{F} R$ Coll Physicians Lond 1973 7:132-44.

5 World Health Organisation. International classification of diseases, 9th revision. Geneva: WHO, 1977.

6 Breslow NE, Day NE. Statistical methods in cancer research Vol II. The design and analysis of cohort studies. Lyon: International Agency for Research on Cancer, 1987.

7 Checkoway H, Pearce N, Hickey JLS, Dement JM Latency analysis in occupational epidemiology. Arch Environ Health 1990;45:95-100.

8 Greenberg M. Ad hoc occupational mortality studies. In: Drever F, ed. Chapter 15. Occupational health decennial Drever F, ed. Chapter 15. Occupatic

9 Darby SC, Kendall GM, Fell TP, O'Hagan JA, Muirhead CR, Ennis JR, et al. Mortality and cancer incidence in UK participants in UK atmospheric nuclear weapons tests and experimental programmes. London: HMSO, 1988. (NRPB report R214.)

10 Darby SC, Kendall GM, Fell TP, O'Hagan JA, Muirhead $\mathrm{CR}$, Ennis JR, et al. A summary of mortality and incidence of cancer in men from the United Kingdom who participated in the United Kingdom's atmospheric nuclear weapons tests and experimental programmes. BMF 1988;296:332-8.

11 Darby SC, Muirhead CR, Doll R, Kendall GM, Thakrar B. Mortality among United Kingdom servicemen who served abroad in the 1950 s and 1960s. Br F Ind Med 1990;47:793-804.

12 Darby SC, Kendall GM, Fell TP, Doll R, Goodill AA, Conquest AJ, et al. Further follow-up of mortality and incidence of cancer in men from the United Kingdom who participated in the United Kingdom's atmospheric who participated in the United Kingdom's atmospheric nuclear weapons tests

13 Fox AJ, Collier PF. Low mortality rates in industrial cohort studies due to selection for work and survival in the industry. Br f Prev Soc Med 1976;30:225-30.

14 Charpentier P, Ostfeld AM, Hadjimichael OC, Hester R. The mortality of US nuclear submariners, 1969-82. $f$ Occup Med 1993;35:501-9.

15 Heasman MA, Lipworth L. Accuracy of certification of cause of death. A report on a survey conducted in 1959 in 75 hospitals of the National Health Service to obtain information on the extent of agreement between clinical and post-mortem diagnoses. Studies on medical and population subjects; no 20. London: General Register Office, HMSO, 1966.

16 Rafnsson V, Gunnarsdóttir H. Risk of fatal accidents occurring other than at sea among Icelandic seamen. BMF 1993;306:1379-81. 